\title{
Correction to: Resonance assignments of a VapC family toxin from Clostridium thermocellum
}

\author{
Chen Wang ${ }^{1,2,3} \cdot$ Jinsong Xuan ${ }^{1} \cdot$ Qiu Cui $^{2,3} \cdot$ Yingang Feng ${ }^{2,3}$ (1)
}

Published online: 9 July 2020

(c) Springer Nature B.V. 2020

\section{Correction to: \\ Biomolecular NMR Assignments (2016) 10:367-371 https://doi.org/10.1007/s12104-016-9702-y}

In the original publication of the article, the authors found a misquote in the Reference section.

The citation to Geerds et al. (2014) is incorrect because the protein VapB in this reference is a completely unrelated protein although it has the same name as the antitoxin VapB. Therefore, the following cited reference should be deleted:

Geerds C, Wohlmann J, Haas A, Niemann HH (2014) Structure of Rhodococcus equi virulence-associated protein B (VapB) reveals an eight-stranded antiparallel $\beta$-barrel consisting of two Greek-key motifs. Acta Crystallogr F 70:866-871. https://doi.org/10.1107/S2053230X14009911
The authors would like to thank Prof. Albert Haas in University of Bonn, Germany for indicating this misquote.

Publisher's Note Springer Nature remains neutral with regard to jurisdictional claims in published maps and institutional affiliations.
The original article can be found online at https://doi.org/10.1007/ s12104-016-9702-y.

Jinsong Xuan

jsxuan@sas.ustb.edu.cn

$\bowtie$ Yingang Feng

fengyg@qibebt.ac.cn

1 Department of Biological Science and Engineering, School of Chemical and Biological Engineering, University of Science and Technology Beijing, 30 Xueyuan Road, Beijing 100083, China

2 Shandong Provincial Key Laboratory of Energy Genetics, Qingdao Institute of Bioenergy and Bioprocess Technology, Chinese Academy of Sciences, 189 Songling Road, Qingdao 266101, China

3 CAS Key Laboratory of Biofuels, Qingdao Institute of Bioenergy and Bioprocess Technology, Chinese Academy of Sciences, 189 Songling Road, Qingdao 266101, China 